\title{
Geschlechts-Krankheiten.
}

\section{Syphilis des Nervensystems und der Sinnesorgane.}

\begin{abstract}
Guszmann, J. und Hudovernig, C. Über die Beziehungen der tertiären Lues zur Tabes dorsalis und Paralysis progressiva. Monatsh. f. prakt. Dermat. Bd. XL.

Guszmann und Hudovernig fanden bei ihren tertiären Kranken, welche Syphilis vor mindestens 3 Jahren erworben hatten, bloß in $44 \%$ der Fälle gesundes Nervensystem, hingegen Tabes, Paralysis progr. und Tabesparalyse bei $46 \%$ und mit Hinzurechnung der verdächtigen Fälle bei $54 \%$. Daher erscheint den beiden Autoren der enge Zusammenhang von Tabes und Paralyse mit Syphilis als gewiß und unzweifelbar. Bei der Entwickluug dieser Erkrankungen kommt der Belastung die hervorragendste prädisponierende Rolle $\mathrm{zu}$, da nach $G$. und Hs. Statistik von den neuropathisch belasteten tertiären Syphilitikern $64 \%$, von den nicht belasteten bloB $41 \%$ an einer der in Betracht kommenden Nervenkrankheiten erkrankten. Das Intervall zwischen Infektion und Beginn der Nervenkrankheit ist verschieden groß: es schwankte vơn 1-27 Jahren, im Mittel 71/2 Jahre. Ein Einfluß der Heredität auf eine etwaige Beschleunigung der Entwicklung der Nervensystemerkrankung ließ sich nicht nachweisen, ebensowenig ein besonderer Einfluß der vorausgegangenen antiluetischen Behandlung auf das Entstehen der Tabes oder Paralyse beziehungsweise auf die Länge des Intervall zwischen Infektion und Beginn der Nervenkrankheit. Die Frage, ob die von den Autoren unternommene antiluetische Behandlung den Zustand des Nervensystems der kranken tertiären Syphilitiker zu beeinflussen vermag, konnten sie nicht einheitlich beantworten. Als Primärsymptome der Nervenkrankheiten fanden sie lanzinierende Schmerzen und Blasenstörungen, dagegen zumeist keine schweren Störungen seitens der $\mathrm{Pr}$ pillen (zumeist nur träge Lichtreaktion). Waelsch (Prag).
\end{abstract}




\section{Syphilis der Eingeweide.}

Thiemann, H. Ein Fall von Nephritis syphilitica acuta. Münchener Medizinische Wochenschrift. 52. Jahrgang. Nr. 5.

Als kasuistischer Beitrag berichtet Thi e m a n $\mathrm{n}$ über einen einwandfreien Fall von Nephritis syphilitica acuta. Die vorher gesunden Nieren erkranken parallel mit den übrigen syphilitischen Erscheinungen. Nach Sublimatinjektionen versehwindet die Albuminurie und die übrigen Symptome der Nephritis.

Hermann F a bry (Göttingen).

König. Die Bedeutung der Lebersyphilis für die Diagnose der Bauchgeschwülste. Berliner klin. Wochenschr. 1905. Nr. 6. p. 137.

König bespricht an der Hand dreier Fälle die auf Syphilis zurückzuführenden schmerzhaften Geschwulstbildungen der Leber. Sie können sich darstellen: 1. als flächenhaft in der Substanz der Leber gelegene meist harte, in der Regel ungleiche Schwellungen, welche innerhalb der Perkussionsgrenzen der Leber liegen; 2. als anscheinend von der Leber getrennte, öfter sehr bewegliche knollige, meist rundliche, nierenförmige etc. Geschwülste, welche mit der Leber gestielt zusammenhängen, einen Teil derselben, zuweilen einen recht großen darstellen! Hinsichtlich der Therapie hält es König für verfehlt zu behaupten, daß die Diagnose Lues ohne weiters jeden blutigen Heilversuch ausschließt. Es läßt sich vielmehr nur von Fall zu Fall entscheiden, ob man durch Operation die Krankheit entfernen darf und soll.

W. Bornemann (Frankfurt a. M.).

Riedel, Jena. Über die fieberhaft verlaufende Lues der Gallenblase und Gallengänge sowie der Leber. Mitteilnngen aus den Grenzgeb. der Mediz. u. Chir. 1904. Bd. XIV. H. I u. II. Art. I.

Nach einleitender Besprechung der Differentialdiagnostik der auf Gallenblase und Gallengänge lokalisierten Lebersyphilis und Hinweis auf die diagnostischen Schwierigkeiten, die die Lues verursacht, wenn gleichzeitig andere Krankheiten auftreten, teilt $\mathrm{Riedel}$ aus dem reichen Schatze seiner Erfahrungen eine Reihe seltener, aber höchst instruktiver Krankengeschichten unter Anfügung einer ausführlichen Epikrise mit. Dieselben betreffen 3 Fälle von fieberhaft verlaufender Cholecystitis luetica ohne Ikterus, einen besonders interessanten Fall von fieberhaft verlaufender Leberlues, der Cholecystitis luetica vorgetäuscht hatte und bei dem nach der Probelaparatomie das Fieber wie abgeschnitten war und einen Fall von Cholecystitis und Cholangitis luetica mit Ikterus Dazwischen flicht Riedel die Krankengeschichten einer auf Bacterium coli-Infektion beruhenden Cholecystitis acuta sine concremento, zweier larvierter Appendicitisfälle, die im Verdachte standen, Leber- resp. Gallenganglues zu haben, ein. Zum Schluß weist Riedel darauf hin, daß, weil Leberlues öfter schmerzlos verläuft, man bei schmerzlos ver- 